\title{
A comparative study of spectral auroral intensity predictions from multiple electron transport models
}

Guy Grubbs II ${ }^{1,2 *}$, Robert Michell ${ }^{3,4}$, Marilia Samara ${ }^{3}$, Donald Hampton ${ }^{5}$, James Hecht ${ }^{6}$, Stanley Solomon ${ }^{7}$, and Jorg-Micha Jahn ${ }^{1,2}$

\author{
${ }^{1}$ Department of Physics and Astronomy, University of Texas at San Antonio, San Antonio, Texas, USA. \\ ${ }^{2}$ Space Science and Engineering, Southwest Research Institute, San Antonio, Texas, USA. \\ ${ }^{3}$ NASA Goddard Space Flight Center, Greenbelt, Maryland, USA. \\ ${ }^{4}$ Department of Astronomy, University of Maryland, College Park, Maryland, USA \\ ${ }^{5}$ Geophysical Institute, University of Alaska Fairbanks, Fairbanks, Alaska, USA. \\ ${ }^{6}$ Space and Environment Technology Center, The Aerospace Corporation, Los Angeles, California, USA \\ ${ }^{7}$ National Center for Atmospheric Research, University Corporation for Atmospheric Research, Boulder, Colorado, USA.
}

\section{Key Points:}

- Transport models are compared using predicted emission intensities as well as in situ data

- Chemical reaction and emission rates of the GLOW model are updated using recent publications

- Similar emission yield is predicted by each for varying electron and atmospheric values

\footnotetext{
*currently at: Department of Physics, Catholic University of America, Washington, District of Columbia, USA.

$\dagger$ currently at: NASA Goddard Space Flight Center, Greenbelt, Maryland, USA.

Corresponding author: Guy Grubbs II, guygrubbs@gmail.com
} 


\begin{abstract}
It is important to routinely examine and update models used to predict auroral emissions resulting from precipitating electrons in Earth's magnetotail. These models are commonly used to invert spectral auroral ground-based images to infer characteristics about incident electron populations when in situ measurements are unavailable. In this work, we examine and compare auroral emission intensities predicted by three commonly used electron transport models using varying electron population characteristics. We then compare model predictions to same-volume in situ electron measurements and ground-based imaging to qualitatively examine modeling prediction error. Initial comparisons showed differences in predictions by the GLobal airglOW (GLOW) model and the other transport models examined. Chemical reaction rates and radiative rates in GLOW were updated using recent publications and predictions showed better agreement with the other models and the samevolume data, stressing that these rates are important to consider when modeling auroral processes. Predictions by each model exhibit similar behavior for varying atmospheric constants, energies, and energy fluxes. Same-volume electron data and images are highly correlated with predictions by each model, showing that these models can be used to accurately derive electron characteristics and ionospheric parameters based solely on multispectral optical imaging data.
\end{abstract}

\title{
1 Introduction and Background
}

Auroral events suggest signatures of acceleration processes in the Auroral Acceleration Region (AAR), Magnetosphere-Ionosphere (MI) coupling region, and magnetotail [Birn et al., 2012]. Ground-based imaging of auroral intensities, spectra, and structures are used to examine these acceleration processes and increase our understanding of the complex physics in each of these regions [Paschmann et al., 2003]. Observed intensities and their ratios are used to predict precipitating electron characteristics through inversion of electron transport modeling [Rees and Jones, 1973; Hecht et al., 2006]. A transport model simulates the movement and interaction of particles through the atmosphere and characterizes their effect on that atmosphere. It is important to periodically examine, update, and compare the different electron transport models in order to ensure accuracy in these simulations and predictions. Three commonly used electron transport models are examined and compared in this work: Electron TRANSport (ETRANS), Boltzmann 3-Constituent (B3C), and Modified GLobal AirglOW (ModGLOW).

There has been a limited number of comparisons made between these models in the past. Lummerzheim and Lilensten [1994] compared ETRANS, B3C, and GLOW to auroral observations and calculated a $15-20 \%$ uncertainty in the derived total energy flux from model inversions. Collision cross-sections and secondary electron production were shown to have a considerable impact on simulation results. Solomon [2001] examined B3C and GLOW using Monte Carlo techniques and found similar ionization rates for identical electron energy inputs. Fang et al. [2008] calculated a 6-15\% scaling factor needed for GLOW ionization rates to be similar to ETRANS at the same energies. These model comparisons mainly examined differences in ionization rates and collision cross-sections, but there are no known comparisons of auroral intensities predicted by the models for similar input parameters.

In this research, we directly compare electron transport model volume emission rates for identical precipitating electron populations. The GLOW model is modified with chemical reaction rates and cross-sections from recent literature and included in these comparisons. These models are then compared to ground-based imaging and conjugate in situ electron measurements. The aim is to characterize and benchmark these electron transport models for use by the ionosphere/thermosphere modeling community. 
Table 1. A list and description of the different atmospheric, ionospheric, and plasma transport models used in the auroral signature predictions. MSIS encompasses both the MSIS-90 and NRLMSISE-00 models. Output parameters are a function of altitude within the range specified.

\begin{tabular}{|c|c|c|}
\hline Name & Alt. $(\mathrm{km})$ & Output \\
\hline \multicolumn{3}{|c|}{ Neutral Atmosphere Model Input: Date, Time, Geo. Location } \\
\hline MSIS [Picone et al., 2002] & $0-1000$ & $T_{n}, N_{n}\left(\mathrm{O}, \mathrm{O}_{2}, \mathrm{~N}, \mathrm{~N}_{2}, \mathrm{H}, \mathrm{He}, \mathrm{Ar}\right)$ \\
\hline SNOE [Marsh et al., 2004] & $97.5-150$ & $N_{n}(\mathrm{NO})$ \\
\hline SAG-2 [Shroll et al., 2003] & $0-1000$ & $T_{n}, N_{n}\left(\mathrm{O}, \mathrm{O}_{2}, \mathrm{~N}, \mathrm{~N}_{2}, \mathrm{NO}, \mathrm{H}, \mathrm{He}\right)$ \\
\hline \multicolumn{3}{|c|}{ Ionosphere Model Input: Date, Time, Geo. Location, $T_{n}, N_{n}$} \\
\hline IRI [Bilitza et al., 2014] & $60-2000$ & $T_{e}, T_{i}, N_{e}, N_{i}\left(\mathrm{O}^{+}, \mathrm{O}_{2}^{+}, \mathrm{N}^{+}, \mathrm{H}^{+}, \mathrm{He}^{+}, \mathrm{NO}^{+}\right)$ \\
\hline FAIM [Anderson et al., 1989] & $180-1000$ & $T_{e}, T_{i}, N_{e}, N_{i}\left(\mathrm{O}^{+}, \mathrm{O}_{2}^{+}, \mathrm{N}^{+}, \mathrm{H}^{+}, \mathrm{He}^{+}, \mathrm{NO}^{+}\right)$ \\
\hline \multicolumn{3}{|c|}{ Geomagnetic Model Input: Date, Time, Geo. Location } \\
\hline IGRF [Thébault et al., 2015] & $0-30000$ & Dip Angle, $|\mathrm{B}|$ \\
\hline GEO-CGM [Gustafsson et al., 1992] & $0-40000$ & Dip Angle, $|\mathrm{B}|$ \\
\hline \multicolumn{3}{|c|}{ Transport Model Input: $T_{n}, T_{i}, T_{e}, N_{n}, N_{i}$, Dip Angle, |B|, e ${ }^{-}$spectra } \\
\hline ETRANS [Lummerzheim, 1987] & $80-800$ & $I_{\lambda}(427.8,844.6 \mathrm{~nm})$ \\
\hline B3C [Strickland et al., 1992] & $90-800$ & $I_{\lambda}(427.8,557.7,844.6 \mathrm{~nm})$ \\
\hline GLOW [Solomon, 2001] & $80-950$ & $I_{\lambda}(427.8,557.7,844.6 \mathrm{~nm})$ \\
\hline
\end{tabular}

\section{Modeling Description}

The different models used in this work are listed in Table 1 and include: International Reference Ionosphere (IRI), Fully Analytical Ionospheric Model (FAIM), Naval Research Laboratory Mass Spectrometer and Incoherent Scatter (MSIS-90 or NRLMSISE00), Student Nitric Oxide Explorer Model (SNOE), SHARC/SAMM2 Atmosphere Generator (SAG-2), the International Geo Reference Field (IGRF-12), and the GEOcentric to Corrected GeoMagnetic Model (GEO-CGM). The subscript and labels inside the parantheses give the species, $T$ is defined as the temperature in Kelvin, $N$ as the number density in particles per cubic centimeter, dip angle as the magnetic field zenith location in the FoV, $|B|$ as the magnetic field strength, and $I_{\lambda}$ as the intensity of the given auroral line in Rayleighs. All input and output parameters are a function of altitude.

The ETRANS, B3C, and GLOW models (named for the underlying transport models each one uses) consist of the four main model types listed in Table 1: a neutral atmosphere model, an ionospheric model, a geomagnetic model, and an electron transport model. A neutral atmosphere model is used to calculate the background neutral densities and temperatures for a given date and location. An ionosphere model uses the neutral parameters to calculate the background ion and electron temperatures and densities in the colocated region. A geomagnetic model uses the date and location to calculate strength and dip angle of the magnetic field, which lies parallel to the electron transport path. Finally, electron transport modeling simulates collisions, chemical reaction rates, radiative rates, and many other parameters for a given precipitating electron population [Rees and Jones, 1973; Strickland et al., 1999; Solomon, 2017]. The results of these models include electron heating, ionization rates, volume emission rates, and many other valuable parameters. This work is concentrated specifically on the resulting spectral auroral emissions. The spectral emissions described in Table 2 are among those most commonly observed and have short radiative lifetimes. Therefore, the 427.8, 557.7, and $844.6 \mathrm{~nm}$ spectral emissions are the focus in this study. 
Table 2. Spectral emission lines, source species, corresponding electron population characteristics, and radiative lifetimes [Steele and McEwen, 1990; Paschmann et al., 2003; Kelley, 2009]

\begin{tabular}{cccc}
\hline$\lambda(\mathrm{nm})$ & Species & Source $\mathrm{e}^{-}$Characteristics & Lifetime $(\mathrm{s})$ \\
\hline 427.8 & $\mathrm{~N}_{2}$ & $\propto$ Total Energy Flux & $10^{-7}$ \\
557.7 & $\mathrm{O}$ & $1 \mathrm{keV} \leq \mathrm{e}^{-}$Energy $\leq 10 \mathrm{keV}$ & .74 \\
844.6 & $\mathrm{O}$ & $\mathrm{e}^{-}$Energy $\leq 1 \mathrm{keV}$ & $10^{-7}$ \\
\hline
\end{tabular}

The precipitating electrons simulated in each model are Maxwellian with a lowenergy tail [Meier et al., 1989]. Two parameters are used to describe these populations: total energy flux $(Q)$ and characteristic energy $\left(E_{o}\right)$. In addition the models may vary the atmospheric constant, $f_{o}$, a unitless parameter which gives the ratio of the columnintegrated $\mathrm{O}$ density to the column integrated $\mathrm{N}_{2}$ density. MSIS atomic oxygen densities at each altitude are multiplied by $f_{o}$ in order to correct for oxygen outflow. The $f_{o}$ value varies depending on many characteristics that affect the atmosphere (such as auroral activity, atmospheric heating, and oxygen outflow). Detailed methods involving the calculation and use of the $f_{o}$ parameter are described in Hecht et al. [2006] and Hecht et al. [2008]. Modeling results presented here are a function of $f_{o}$ and $E_{o}$, and given in units of yield (Rayleighs $/ Q$ ) and are assumed to scale linearly with total energy flux. ETRANS and GLOW are modified to use identical background models for this study, while B3C source code is proprietary and could not be modified (details given below).

\subsection{ETRANS}

ETRANS is based on multi-stream electron transport modeling described in Rees and Jones [1973] and Jones and Rees [1973]. This model was updated to the current version in Lummerzheim and Lilensten [1994] and the detailed electron impact cross-sections and chemistry included are available in Lummerzheim [1987]. Sample electron distributions from a sounding rocket were used for model validation in Lummerzheim et al. [1989] and Rees and Lummerzheim [1989]. In this work, ETRANS was updated to include the IRI-16, NRLMSISE-00 and IGRF-12 models to ensure that the same set of input parameters was used for both ETRANS and GLOW. ETRANS does not include SNOE modeling of the NO neutral density due to a lack of integration for new species in the software.

\section{$2.2 \mathrm{B3C}$}

This electron transport model is described in Strickland et al. [1989] and further developed in Strickland et al. [1992]. Results for intensity line ratios have been published and tested using incoherent scatter radar observations in Hecht et al. [2006], Hecht et al. [2008], and Kaeppler et al. [2015]. The B3C model uses the MSIS-90 model for the neutral atmosphere combined with SAG-2 software which empirically predicts many other neutral densities not used in this study [Shroll et al., 2003]. A detailed list of the current cross sections and emission rates used are available in Appendices A-C of Strickland et al. [1999]. The FAIM model is given the neutral atmosphere as input and produces the plasma densities at the same altitudes. The neutral and plasma densities are combined with the GEO-CGM produced magnetic field and the electron precipitation is simulated through the atmosphere by $\mathrm{B} 3 \mathrm{C}$.

\subsection{Modified GLOW (ModGLOW)}

The GLOW v.98 model, described in A and B of Solomon [1989] and further developed in Solomon [2001] and Solomon [2017], uses a Monte Carlo two-stream technique to model the electron transport through the atmosphere. This model has been tested in three 
case studies using ISR data and ground-based imaging by Kaeppler et al. [2015]. GLOW was written using IRI-98, NRLMSISE-00, and SNOE [Marsh et al., 2004] to model atmosphere and plasma characteristics, and was updated to use IRI-16 in this study. Electron impact cross-sections and chemical reactions used in the original GLOW are given in Appendix A and B of [Solomon et al., 1988].

Inspection of the radiative and chemistry reaction rates revealed discrepancies between GLOW and values from the most recent sources. Many reactions have been updated for the modified version of the model (ModGLOW) used to produce results in this work. The aim is using the most accurate chemistry modeling available. A summary of the changes can be found in Appendix A and the modified source code including these changes is provided as a branch to the original source online. The modifications to GLOW result in offsets in predictions for each emission line but do not fundamentally change the model behavior as functions of $Q, E_{o}$, and $f_{o}$. The modifications to GLOW resulted in the following changes in intensity predictions: $427.8 \mathrm{~nm}$ yield decreased by approximately $6 \%, 557.7 \mathrm{~nm}$ yield increased by approximately $37 \%$, and $844.6 \mathrm{~nm}$ increased by approximately $9 \%$.

\section{Results}

\subsection{Modeling Comparison}

An overview of the model comparison results are shown in Figure 1 and an examination of the different spectra is given in more detail below. The yield of each model simulation is shown for each emission line analyzed, identified by column (model name) and row (emission wavelength).

\subsubsection{8 nm Emissions}

The $427.8 \mathrm{~nm}$ emission yield is displayed in the top row of Figure 1. Similar characteristics are observed for each model, such as an inverse relationship between the predicted yield and the $f_{o}$ value for low $E_{o}$. At $E_{o}$ values greater than $5 \mathrm{keV}$, the predicted yield became independent of $f_{o}$. B3C and GLOW approached a constant yield of approximately $250 \mathrm{R} / Q$ at high energies, while predictions by ETRANS began to decline below $200 \mathrm{R} / Q$.

\subsubsection{7 $\mathrm{nm}$ Emissions}

$557.7 \mathrm{~nm}$ emission yield is shown in the middle row of Figure 1 and was only available for the B3C and GLOW models since it is not natively simulated in ETRANS. The predictions are similar for both models, predicting a maximum yield at approximately 3 $\mathrm{keV}$ for $E_{o}$. The $557.7 \mathrm{~nm}$ emission predicitons are proportional to the $f_{o}$ values and approach constant yields for $f_{o} \geq 1.00$ in both models.

\subsubsection{6 $\mathrm{nm}$ Emissions}

$844.6 \mathrm{~nm}$ emission yield is shown in the bottom row of Figure 1 and the same behavior is observed in the predictions by each model. The predicted yield is inversely proportional to $E_{o}$ and proportional to $f_{o}$ values, although an offset of approximately 200$300 \mathrm{R} / \mathrm{Q}$ is visible when comparing by model.

\subsection{Data Comparison}

In addition to comparing theoretical yield, each model is also compared using in situ electron data from a sounding rocket mission and common-volume emissions observed by ground-based imaging. The data and simulation predictions are presented in Figure 2. 

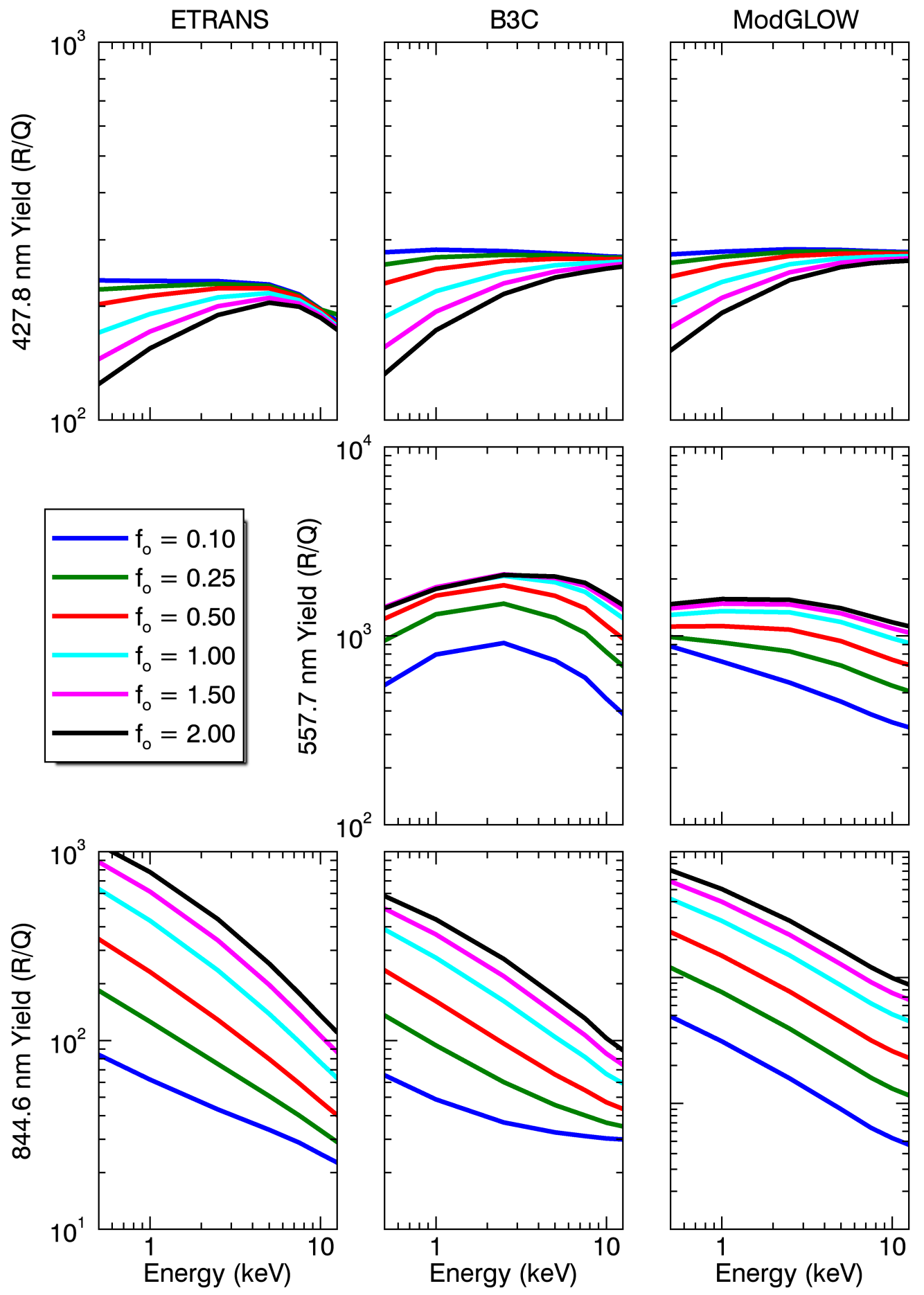

Figure 1. Predictions made by ETRANS, B3C, and modified GLOW (left, middle, and right columns, respectively) with varying values of characteristic energy, $E_{o}$, and atmospheric constant, $f_{o}$, for the 427.8 $\mathrm{nm}, 557.7 \mathrm{~nm}$, and $844.6 \mathrm{~nm}$ intensity (top, middle, and bottom rows, respectively). The same emission line characteristics and relationships are observed across all models. 
Table 3. Correlation coefficients of predictions versus observed intensities

\begin{tabular}{c|ccc}
\hline $\mathrm{R}$ & ETRANS & B3C & ModGLOW \\
\hline $427.8 \mathrm{~nm}$ & .97 & .97 & .96 \\
$557.7 \mathrm{~nm}$ & - & .94 & .96 \\
$844.6 \mathrm{~nm}$ & .95 & .96 & .94 \\
\hline
\end{tabular}

Observed emissions (black) are qualitatively compared to predicted emissions by GLOW (red), ETRANS (green), and B3C (blue) made using in situ electron data from Michell et al. [2016]. Observations and predictions compare well for most of the flight with the exception of observations near the edge of the imager FoV (> $400 \mathrm{~s}$ ), where error in observations becomes large due to imager calibration errors [Grubbs et al., 2016]. Each model makes predictions with the assumption that measurements are taken at Magnetic Zenith (MZ), so mean prediction error is presented as a function of distance from MZ. Identical atmospheric and electron distribution parameters are used in each simulation. An $f_{o}$ value of .5 is used, which is consistent with Global UltraViolet Imager (GUVI) $\mathrm{O} / \mathrm{N}_{2}$ estimates during the same time period.

The correlation coefficient $(\mathrm{R})$ of each prediction versus observed intensity is presented in Table 3 as a function of model and emission wavelength. GLOW and ModGLOW predictions show the same behavior throughout the flight, so the correlation coefficient is identical for both versions of the transport code. Each model has a high correlation coefficient for each wavelength examined $(\mathrm{R}>.94)$, meaning that there is a positive linear relationship between the predicted and observed emissions.

\section{Discussion}

Each model predicts an inverse relationship between $f_{o}$ and $427.8 \mathrm{~nm}$ intensity yield. This behavior is expected due to the increase in the oxygen source population $(O)$ with increase in $f_{o}$, which dissipates the electron energy collisionally before it reaches the $N_{2}$ population ( $427.8 \mathrm{~nm}$ source). The $427.8 \mathrm{~nm}$ intensity yield for ETRANS decreases for all $f_{o}$ values at energies above $10 \mathrm{keV}$, most likely due to missing chemistry which would also predict 557.7 emissions. The complexity of the ETRANS source code and the storage of cross-sections and chemistry in raw binary format does not allow for testing of this hypothesis, however. B3C and GLOW yield for $557.7 \mathrm{~nm}$ and $844.6 \mathrm{~nm}$ is proportional to the $f_{o}$ value due to the increase in the $O$ population with increasing $f_{o}$. All models show a steady decrease in yield of $844.6 \mathrm{~nm}$ with increased $E_{o}$ due to lower energy electrons being the primary source of these emissions.

Figure 1 shows evidence that yield from the $\mathrm{O}$ and $\mathrm{N}_{2}$ populations reaches saturation if the atmospheric constant is too high or too low, respectively. Variation of this parameter shows that the GLOW model saturates less quickly for $557.7 \mathrm{~nm}$ emissions, however. The differences in the emission yield of B3C and GLOW provides evidence that the radiative and chemical reaction rates are important in the simulations and should be updated as more data become available. Further collaboration between the modeling groups will help identify and resolve any other differences, as well. GLOW and ModGLOW showed the same behavior for $Q$ and $E_{o}$ versus emission intensities, but ModGLOW predicted absolute intensities that were more accurate for each line observed when compared to in situ electron measurements.

The ETRANS model, which provides heritage and the framework for the models used currently, does not natively predict the $557.7 \mathrm{~nm}$ intensity line which is one of the most intense auroral lines observed. Post-processing of ETRANS simulations, such as that used in Ni et al. [2012], can be used to produce these emissions but this software 

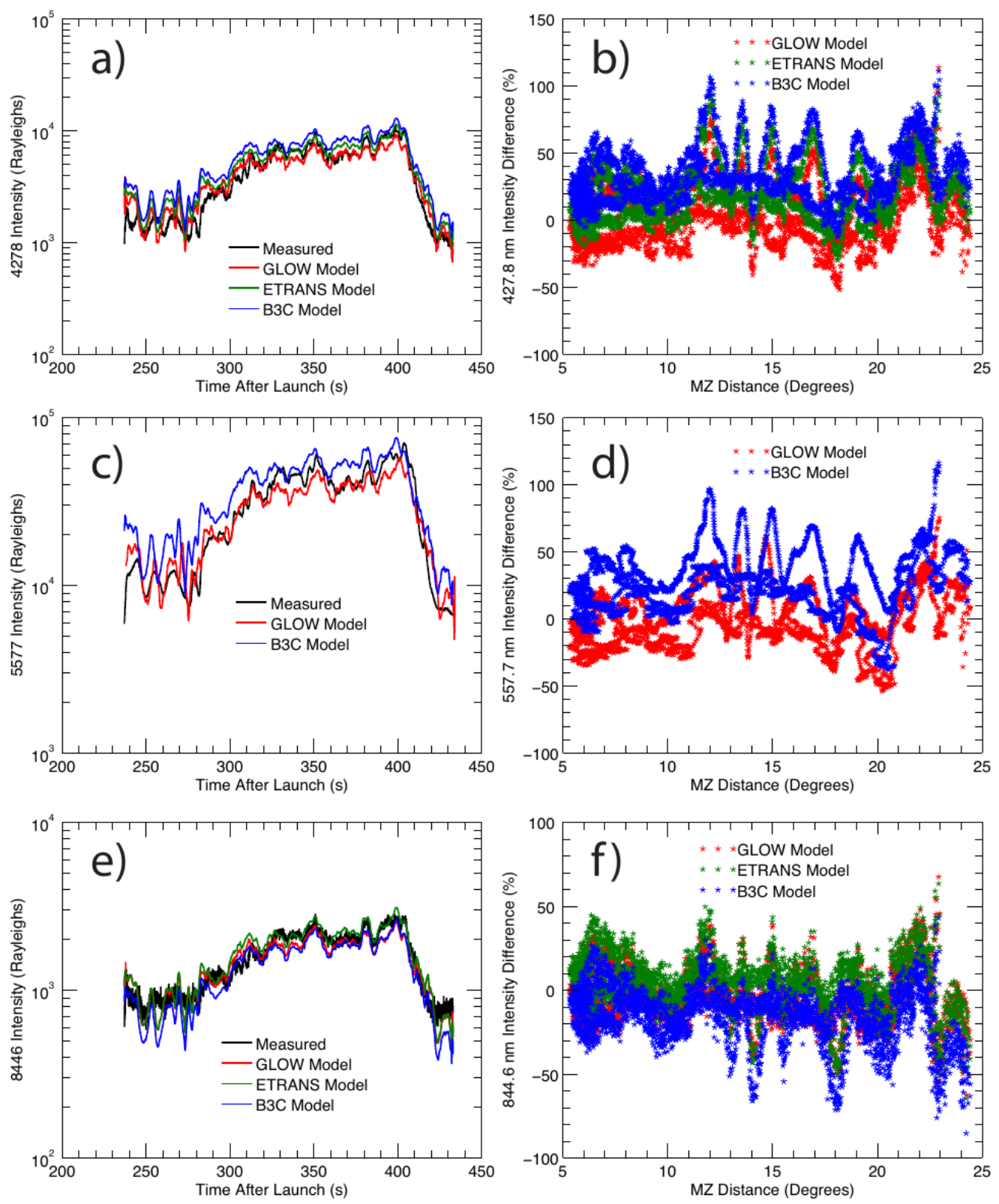

Figure 2. The observed emissions (black) and predicted emissions of modified GLOW (red), ETRANS (green), and B3C (blue) are shown on the left as a function of rocket flight time for the 427.8 (a), 557.7 (c), and 844.6 (e) nm spectral lines. The same structure is visible in observations and predictions with the exception of times after $400 \mathrm{~s}$ ( $>20^{\circ}$ zenith distance). 
is not included in the current distribution. In addition, the length and complexity of the ETRANS software makes upgrades to the chemistry and transport processes difficult compared to that of GLOW. The B3C and updated GLOW model are found to have similar predictions for the 427.8, 557.7, and $844.6 \mathrm{~nm}$ spectral lines. An in-depth analysis of the differences between the chemistry and cross-sections is outside of the scope of this research, but will provide more information and feedback for future modeling. The different modeling techniques employed in GLOW and B3C produce predictions of similar magnitudes for all modeled wavelengths, validating the approach of each technique. In addition, Figure 2 compares model predictions and observed emissions for a recent sounding rocket mission and Table 3 shows high correlation coefficients for each model.

In Figure 3a, an inversion map is produced for the observations during the rocket flight by assuming a Maxwellian electron distribution and running GLOW over the parameter space of $Q$ and $E_{o}$. The $427.8 \mathrm{~nm}$ absolute intensity versus the 844.6/557.7 nm intensity ratio is then plotted in the inversion map and the $E_{o}$ and $Q$ values are estimated for the observation period. Figure $3 \mathrm{~b}$ shows the $844.6 / 557.7 \mathrm{~nm}$ intensity during the launch period and Figure $3 \mathrm{c}$ compares the predicted $E_{o}$ to the measured $E_{o}$. The predicted and measured $E_{o}$ values are qualitatively similar. Work in Grubbs II et al. [2017] examines these techniques and their associated errors in detail.

These models are most commonly used in combination with ground-based imaging to deduce information about the precipitating electrons responsible for the aurora. Figure $3 \mathrm{a}$, shows an example of an inversion map that is produced from the output of GLOW by assuming Maxwellian electron distributions over the parameter space of $Q$ and $E_{o}$ values. The model output values for the $427.8 \mathrm{~nm}$ intensity versus the $844.6 / 557.7 \mathrm{~nm}$ intensity ratio are plotted for each $E_{o}$ and $Q$ combination, creating the inversion map. Actual measured auroral intensities at the three modeled wavelengths are compared with the inversion map to determine the $E_{o}$ and $Q$ values that produced the observed auroral intensities. Figure $3 \mathrm{~b}$ shows the $844.6 / 557.7 \mathrm{~nm}$ intensity ratio during the rocket flight and Figure $3 \mathrm{c}$ compares the predicted $E_{o}$ based on the inversion map to the measured $E_{o}$ from the rocket flight. The predicted and measured $E_{o}$ values are qualitatively similar. Grubbs II et al. [2017] examines these techniques and their associated errors in detail.

There are strengths and limitations in each model described in this work. B3C includes time-dependence in the simulations which allows for the time history of electron populations affects on atmospheric densities to be incorporated into the predictions. B3C is proprietary, which makes it less accessible to the modeling community and difficult to modify and test with different parameters (e.g. chemical reaction rates, collision crosssections, and radiative rates). GLOW is open-source and available to the community for modification and testing, but does not natively include time-dependence in the simulations. Liang et al. [2016] have began initial assimilation of time-dependence into GLOW to examine pulsating aurora, but certain physical processes are ignored (e.g. ambipolar diffusion and electron heating. Work is currently being done to include these processes by combining GLOW and the Thermosphere Ionosphere Electrodynamics General Circulation Model (TIE-GCM; Qian et al. [2014]) or GEMINI (Zettergren et al. [2014]) so that there is increased accuracy in emission predictions [Solomon, 2017]. ETRANS source code is available upon request from the University of Fairbanks, AK but is difficult to modify due to the use of raw binary chemistry and cross-section source files. However, ETRANS is multistream capable which can increase the accuracy of predictions for anisotropic electron distributions. The work shown here suggests that the behavior of emissions intensities as a function of precipitating electron energy is similar regardless of the model chosen, but accurate reaction rates will result in more accurate absolute intensity predictions. 
a)

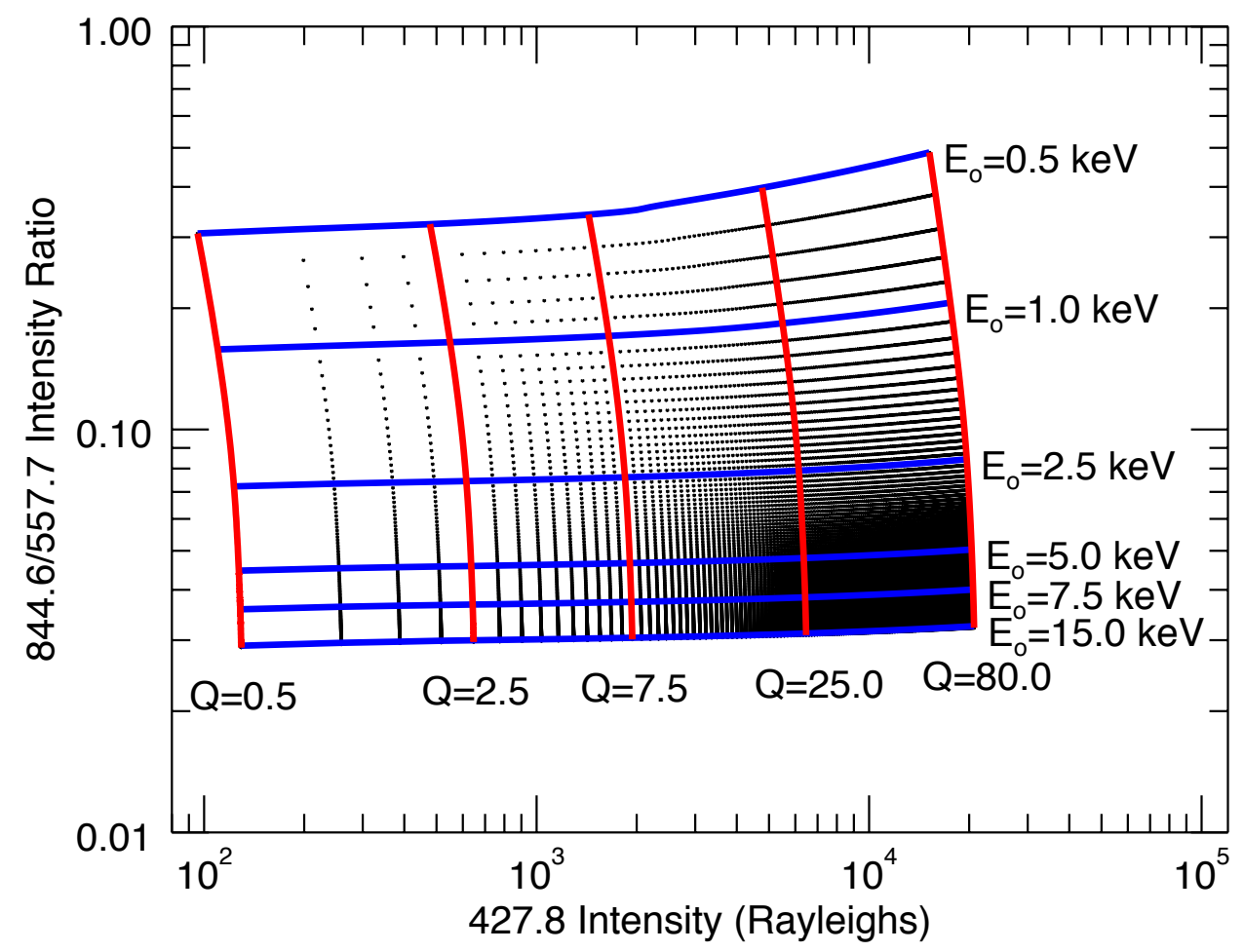

b)

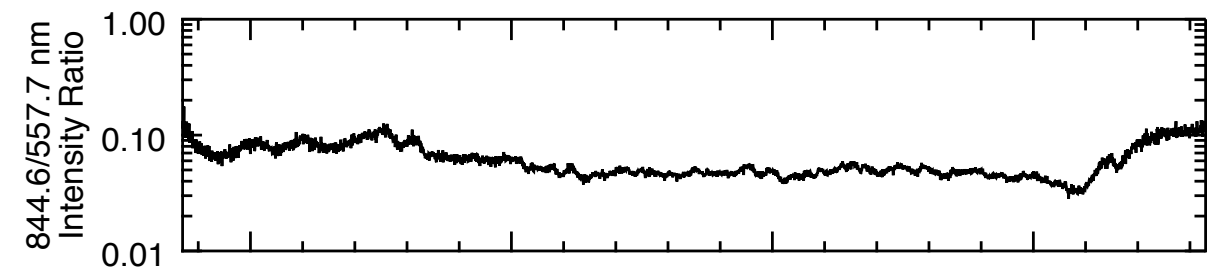

C)

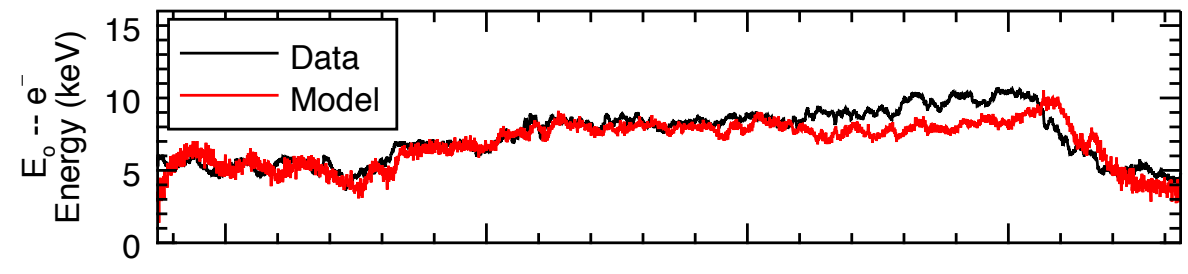

$\begin{array}{ccrcc}\text { UT } & 11: 14: 00 & 11: 14: 50 & 11: 15: 40 & 11: 16: 30 \\ \text { Alt. (km) } & 324.6 & 335.9 & 325.2 & 292.3 \\ \text { ILat. (deg.) } & 67.15 & 67.38 & 67.57 & 67.73 \\ \text { MLT } & 23: 54: 00 & 23: 54: 50 & 23: 55: 40 & 23: 56: 30\end{array}$

Figure 3. (a) An inversion map is derived for varying values of $E_{O}$ (blue) and $Q$ (red) and plotted as a function of the $844.6 / 557.7 \mathrm{~nm}$ intensity ratio versus the $427.8 \mathrm{~nm}$ absolute intensity. (b) The $844.6 / 557.7$ ratio is plotted as a function of time during the rocket launch. (c) The estimated (red) and measured (black) $E_{o}$ are compared as a function of time and are qualitatively similar. 


\section{Conclusion}

Relationships are demonstrated between electron population characteristics, emission line intensities, and emission line ratios using multiple electron transport models and in situ data. Modifications to the chemistry and radiative rates of GLOW result in emission line predictions similar to ETRANS and B3C. Similar relationships are shown between in situ electron populations and the 427.8, 557.7, and $844.6 \mathrm{~nm}$ emissions for all models analyzed, which increases confidence in their predictions. The open source nature of the GLOW code allows for community contributions and feedback, such as the chemical reaction rate changes presented here. The B3C and modified GLOW models include more emission lines and are shown to have accurate predictions, so these models are recommended for analysis of conjugate ground-based imaging and in situ electron population characteristics. These transport codes will be incorporated into global models in order to examine energy transfer between the magnetosphere and ionosphere to better understand processes which occur in these regions.

\section{A: GLOW Reaction Rate Coefficients}

Comparisons of the chemistry used in the GLOW code versus chemical reaction rates published recently revealed many differences. In an attempt to improve the prediction accuracy of GLOW, cross sections and chemical reaction rates were updated using the most recent laboratory data available. Many coefficients given in Appendix A-C of Strickland et al. [1999] were updated during these changes and the tables provided therein have been adapted to show these changes. Focus is given to reactions containing the most prevalent species at auroral altitudes: $\mathrm{O}, \mathrm{N}, \mathrm{O}_{2}, \mathrm{~N}_{2}$, and $\mathrm{NO}$. Excited states and ions of these species are also included. Unless otherwise shown, reactants are assumed to be in their ground state for the given rates. Table A.1 provides the most recent chemistry coefficient rates. Table A.2 gives recombination rates for electrons and different ion species. Table A.3 provides electron quenching rates for excited states of ion species modeled. Radiative rates for modeled spectral lines were also updated and shown in Table A.4. Many of the reaction channels shown were missing or outdated in the GLOW model chemistry, highlighted in grey. Some reaction rates are based on assumptions made in the references, and the references have been provided for verification. Three body collisions were outside of the scope of this work but become important at altitudes below $110 \mathrm{~km}$ [Schunk and Nagy, 2009]. A branch of the open source GLOW software package has been updated to include these changes, and all predictions made in this research are made with the reaction rate coefficients shown. The Vegard-Kaplan emission rate from $\mathrm{N}_{2}$ is described by $A_{V K}$.

Table A.1: Chemical reaction rates updated in the GLOW model.

Adapted from Strickland et al. [1999] and updated with new rates that have become available.

\begin{tabular}{rlrlr}
\hline Reaction & & & Rate Coefficient $\left(\mathrm{cm}^{3} \mathrm{~s}^{-1}\right)$ & Reference \\
\hline $\mathrm{N}_{2}^{+}+\mathrm{O}_{2}$ & $\rightarrow \mathrm{O}_{2}^{+}+\mathrm{N}_{2}$ & $k_{1}$ & $=5.0 \times 10^{-11} \tau_{i}^{-.8}$ \\
$\mathrm{~N}_{2}^{+}+\mathrm{NO}$ & $\rightarrow \mathrm{NO}^{+}+\mathrm{N}_{2}$ & $k_{2}$ & $=7.5 \times 10^{-9} T_{n}^{-.52}$ \\
$\mathrm{~N}_{2}^{+}+\mathrm{O}$ & $\rightarrow$ products & $k_{3}$ & $=1.4 \times 10^{-10} \tau_{i}^{-.44}, T_{i} \leq 1500^{\circ} \mathrm{K}$ \\
& $\left.\rightarrow \mathrm{NO}^{+}+\mathrm{N}^{2} D\right)$ & $k_{3 a}$ & $=5.2 \times 10^{-11} \tau_{i}^{2}, T_{i}>1500^{\circ} \mathrm{K}$ \\
& $\rightarrow \mathrm{O}^{+}+\mathrm{N}_{2}$ & $k_{3 b}$ & $\left.=.07 \tau_{i}^{21} \cdot k_{3}^{21}\right) \cdot k_{3}$ \\
& $\rightarrow \mathrm{NO}^{+}+\mathrm{O}_{2}$ & $k_{4}$ & $=4.1 \times 10^{-10}$
\end{tabular}


Table A.1: Continued

\begin{tabular}{|c|c|c|c|c|}
\hline $\mathrm{O}_{2}^{+}+\mathrm{N}$ & $\begin{array}{l}\rightarrow \text { products } \\
\rightarrow \mathrm{NO}^{+}+\mathrm{O}\left({ }^{1} S\right) \\
\rightarrow \mathrm{NO}^{+}+\mathrm{O}\left({ }^{1} D\right)\end{array}$ & $\begin{array}{l}k_{5} \\
k_{5 a} \\
k_{5 b}\end{array}$ & $\begin{array}{l}=1.65 \times 10^{-10} \\
=.15 \cdot k_{5} \\
=.85 \cdot k_{5}\end{array}$ & [10] \\
\hline $\mathrm{O}^{+}+\mathrm{N}_{2}$ & $\rightarrow \mathrm{NO}^{+}+\mathrm{N}$ & $k_{6}$ & $\begin{array}{l}=1.72 \times 10^{-12}-7.2 \times 10^{-13} \tau_{n} \\
+1.33 \times 10^{-13} \tau_{n}^{2}-9.28 \times 10^{-15} \tau_{n}^{3} \\
+6.40 \times 10^{-16} \tau_{n}^{4}, T_{n} \geq 300^{\circ} \mathrm{K} \\
10^{-12}\left(2.05-.00308 T_{n}\right), T_{n}<300^{\circ} \mathrm{K}\end{array}$ & [4] \\
\hline $\mathrm{O}^{+}+\mathrm{O}_{2}$ & $\rightarrow \mathrm{O}_{2}^{+}+\mathrm{O}$ & $k_{7}$ & $\begin{array}{l}=1.6 \times 10^{-11} \tau_{n}^{-.52} \\
+5.5 \times 10^{-11} e^{-6832 / T_{n}}\end{array}$ & [4] \\
\hline $\mathrm{O}^{+}+\mathrm{NO}$ & $\rightarrow \mathrm{NO}^{+}+\mathrm{O}$ & $k_{8}$ & $=8.0 \times 10^{-13}$ & [7] [8] \\
\hline $\mathrm{N}^{+}+\mathrm{O}_{2}$ & $\begin{array}{l}\rightarrow \text { products } \\
\rightarrow \mathrm{NO}^{+}+\mathrm{O} \\
\rightarrow \mathrm{NO}^{+}+\mathrm{O}\left({ }^{1} D\right) \\
\rightarrow \mathrm{O}_{2}^{+}+\mathrm{N} \\
\rightarrow \mathrm{O}_{2}^{+}+\mathrm{N}\left({ }^{2} D\right) \\
\rightarrow \mathrm{O}^{+}+\mathrm{NO}\end{array}$ & $\begin{array}{l}k_{9} \\
k_{9 a} \\
k_{9 b} \\
k_{9 c} \\
k_{9 d} \\
k_{9 a}\end{array}$ & $\begin{array}{l}=5.5 \times 10^{-10} \\
=.09 \cdot k_{9} \\
=.36 \cdot k_{9} \\
=.35 \cdot k_{9} \\
=.15 \cdot k_{9} \\
=.05 \cdot k_{9}\end{array}$ & [4] [6] \\
\hline $\mathrm{N}^{+}+\mathrm{NO}$ & $\begin{array}{l}\rightarrow \text { products } \\
\rightarrow \mathrm{NO}^{+}+\mathrm{N} \\
\rightarrow \mathrm{N}_{2}^{+}+\mathrm{O}\end{array}$ & $\begin{array}{l}k_{10} \\
k_{10 a} \\
k_{10 b}\end{array}$ & $\begin{array}{l}=6.44 \times 10^{-9} T_{n}^{-.44} \\
=.89 \cdot k_{10} \\
=.11 \cdot k_{10}\end{array}$ & [4] \\
\hline $\mathrm{N}^{+}+\mathrm{O}$ & $\rightarrow \mathrm{N}+\mathrm{O}^{+}$ & $k_{11}$ & $=2.2 \times 10^{-12}$ & [4] [6] [8] \\
\hline $\mathrm{O}^{+}\left({ }^{2} P\right)+\mathrm{N}_{2}$ & $\begin{array}{l}\rightarrow \mathrm{N}_{2}^{+}+\mathrm{O} \\
\rightarrow \mathrm{N}^{+}+\mathrm{NO}\end{array}$ & $\begin{array}{l}k_{12 a} \\
k_{12 b}\end{array}$ & $\begin{array}{l}=2.0 \times 10^{-10} \tau_{n}^{-.5} \\
=1.0 \times 10^{-10}\end{array}$ & $\begin{array}{l}{[4]} \\
{[7]}\end{array}$ \\
\hline $\mathrm{O}^{+}\left({ }^{2} P\right)+\mathrm{O}_{2}$ & $\rightarrow \mathrm{O}_{2}^{+}+\mathrm{O}$ & $k_{13}$ & $=3.1 \times 10^{-10} \tau_{n}^{-.5}$ & [4] \\
\hline $\mathrm{O}^{+}\left({ }^{2} P\right)+\mathrm{O}$ & $\rightarrow \mathrm{O}^{+}+\mathrm{O}$ & $k_{14}$ & $=5.2 \times 10^{-11}$ & {$[4][8]$} \\
\hline $\mathrm{O}^{+}\left({ }^{2} D\right)+\mathrm{N}_{2}$ & $\begin{array}{l}\rightarrow \mathrm{N}_{2}^{+}+\mathrm{O} \\
\rightarrow \mathrm{O}^{+}+\mathrm{N}_{2}\end{array}$ & $\begin{array}{l}k_{15 a} \\
k_{15 b}\end{array}$ & $\begin{array}{l}=1.5 \times 10^{-10} \tau_{n}^{-.5} \\
=8.0 \times 10^{-10}\end{array}$ & $\begin{array}{l}{[4]} \\
{[7]}\end{array}$ \\
\hline $\mathrm{O}^{+}\left({ }^{2} D\right)+\mathrm{O}_{2}$ & $\rightarrow \mathrm{O}_{2}^{+}+\mathrm{O}$ & $k_{16}$ & $=1.0 \times 10^{-10} \tau_{n}^{-.5}$ & [4] \\
\hline $\mathrm{O}^{+}\left({ }^{2} D\right)+\mathrm{NO}$ & $\rightarrow \mathrm{NO}^{+}+\mathrm{O}$ & $k_{17}$ & $=1.2 \times 10^{-9}$ & {$[6][8]$} \\
\hline $\mathrm{O}^{+}\left({ }^{2} D\right)+\mathrm{O}$ & $\rightarrow \mathrm{O}^{+}+\mathrm{O}$ & $k_{18}$ & $=5.0 \times 10^{-12}$ & {$[4][8]$} \\
\hline $\mathrm{N}\left({ }^{2} P\right)+\mathrm{N}_{2}$ & $\rightarrow \mathrm{N}+\mathrm{N}_{2}$ & $k_{19}$ & $=5.0 \times 10^{-17}$ & [3] \\
\hline $\mathrm{N}\left({ }^{2} P\right)+\mathrm{O}_{2}$ & $\rightarrow \mathrm{O}+\mathrm{NO}$ & $k_{20}$ & $=2.5 \times 10^{-12}$ & [3] \\
\hline $\mathrm{N}\left({ }^{2} P\right)+\mathrm{NO}$ & $\rightarrow \mathrm{N}\left({ }^{2} D\right)+\mathrm{NO}$ & $k_{21}$ & $=3.0 \times 10^{-11}$ & [8] \\
\hline $\mathrm{N}\left({ }^{2} P\right)+\mathrm{O}$ & $\begin{array}{l}\rightarrow \text { products } \\
\rightarrow \mathrm{N}+\mathrm{O} \\
\rightarrow \mathrm{N}+\mathrm{O}\left({ }^{1} D\right) \\
\rightarrow \mathrm{N}\left({ }^{2} D\right)+\mathrm{O}\end{array}$ & $\begin{array}{l}k_{22} \\
k_{22 a} \\
k_{22 b} \\
k_{22 c}\end{array}$ & $\begin{array}{l}=2.7 \times 10^{-11} \\
=.81 \cdot k_{22} \\
=.09 \cdot k_{22} \\
=.09 \cdot k_{22}\end{array}$ & [3] \\
\hline
\end{tabular}


Table A.1: Continued

\begin{tabular}{|c|c|c|c|}
\hline & $\rightarrow \mathrm{N}\left({ }^{2} D\right)+\mathrm{O}\left({ }^{1} D\right)$ & $k_{22 d}$ & $=.01 \cdot k_{22}$ \\
\hline $\mathrm{N}\left({ }^{2} P\right)+\mathrm{N}$ & $\rightarrow \mathrm{N}\left({ }^{2} D\right)+\mathrm{N}$ & $k_{23}$ & $=6.0 \times 10^{-13}$ \\
\hline $\mathrm{N}\left({ }^{2} D\right)+\mathrm{N}_{2}$ & $\rightarrow \mathrm{N}+\mathrm{N}_{2}$ & $k_{24}$ & $=1.0 \times 10^{-13} e^{-510 / T_{n}}$ \\
\hline $\mathrm{N}\left({ }^{2} D\right)+\mathrm{O}_{2}$ & $\begin{array}{l}\rightarrow \text { products } \\
\rightarrow \mathrm{NO}+\mathrm{O} \\
\rightarrow \mathrm{NO}+\mathrm{O}\left({ }^{1} D\right)\end{array}$ & $\begin{array}{l}k_{25} \\
k_{25 a} \\
k_{25 b}\end{array}$ & $\begin{array}{l}=6.2 \times 10^{-12} \tau_{n} \\
=.9 \cdot k_{25} \\
=.1 \cdot k_{25}\end{array}$ \\
\hline $\mathrm{N}\left({ }^{2} D\right)+\mathrm{NO}$ & $\rightarrow \mathrm{N}_{2}+\mathrm{O}$ & $k_{26}$ & $=6.7 \times 10^{-11}$ \\
\hline $\mathrm{N}\left({ }^{2} D\right)+\mathrm{O}$ & $\begin{array}{l}\rightarrow \text { products } \\
\rightarrow \mathrm{N}+\mathrm{O} \\
\rightarrow \mathrm{N}+\mathrm{O}\left({ }^{1} D\right) \\
\rightarrow \mathrm{NO}^{+}+\mathrm{e}\end{array}$ & $\begin{array}{l}k_{27} \\
k_{27 a} \\
k_{27 b} \\
k_{27 c}\end{array}$ & $\begin{array}{l}=1.4 \times 10^{-12} \\
=.9 \cdot k_{27} \\
=.1 \cdot k_{27} \\
=2.5 \times 10^{-18} T_{n}^{1 / 2}\left(2205+T_{n}\right) e^{-4410 / T_{n}}\end{array}$ \\
\hline $\mathrm{N}\left({ }^{2} D\right)+\mathrm{O}^{+}$ & $\rightarrow \mathrm{N}^{+}+\mathrm{O}$ & $k_{28}$ & $=1.3 \times 10^{-10}$ \\
\hline $\mathrm{N}+\mathrm{O}_{2}$ & $\rightarrow \mathrm{NO}+\mathrm{O}$ & $k_{29}$ & $=1.5 \times 10^{-11} e^{-3573 / T_{n}}$ \\
\hline $\mathrm{N}+\mathrm{NO}$ & $\rightarrow \mathrm{N}_{2}+\mathrm{O}$ & $k_{30}$ & $\begin{array}{l}=2.2 \times 10^{-11} e^{-160 / T_{n}}, T_{n} \leq 400^{\circ} \mathrm{K} \\
=3.3 \times 10^{-11}, T_{n}>400^{\circ} \mathrm{K}\end{array}$ \\
\hline $\mathrm{N}+\mathrm{O}$ & $\rightarrow \mathrm{NO}+h v$ & $k_{31}$ & $=3.33 \times 10^{-16} T_{n}^{-1 / 2}\left(1.0-.567 \cdot T_{n}^{-1 / 2}\right)$ \\
\hline $\mathrm{O}\left({ }^{1} S\right)+\mathrm{O}_{2}$ & $\begin{array}{l}\rightarrow \text { products } \\
\rightarrow \mathrm{O}+\mathrm{O}_{2} \\
\rightarrow \mathrm{O}\left({ }^{1} D\right)+\mathrm{O}_{2}\end{array}$ & $\begin{array}{l}k_{32} \\
k_{32 a} \\
k_{32 b}\end{array}$ & $\begin{array}{l}=2.32 \times 10^{-12} \exp \left[-\frac{6750-.0151 T_{n}^{2}}{8.314 T_{n}}\right] \\
=.69 \cdot k_{32} \\
=.31 \cdot k_{32}\end{array}$ \\
\hline $\mathrm{O}\left({ }^{1} S\right)+\mathrm{NO}$ & $\begin{array}{l}\rightarrow \text { products } \\
\rightarrow \mathrm{O}+\mathrm{NO} \\
\rightarrow \mathrm{O}\left({ }^{1} D\right)+\mathrm{NO}\end{array}$ & $\begin{array}{l}k_{33} \\
k_{33 a} \\
k_{33 b}\end{array}$ & $\begin{array}{l}=8.0 \times 10^{-11} \\
=.36 \cdot k_{33} \\
=.64 \cdot k_{33}\end{array}$ \\
\hline $\mathrm{O}\left({ }^{1} S\right)+\mathrm{O}$ & $\rightarrow \mathrm{O}+\mathrm{O}$ & $k_{34}$ & $=2.0 \times 10^{-14}$ \\
\hline $\mathrm{O}\left({ }^{1} D\right)+\mathrm{N}_{2}$ & $\rightarrow \mathrm{O}+\mathrm{N}_{2}$ & $k_{35}$ & $=1.8 \times 10^{-11} e^{107 / T_{n}}$ \\
\hline $\mathrm{O}\left({ }^{1} D\right)+\mathrm{O}_{2}$ & $\rightarrow \mathrm{O}+\mathrm{O}$ & $k_{36}$ & $=3.2 \times 10^{-11} e^{67 / T_{n}}$ \\
\hline $\mathrm{O}\left({ }^{1} D\right)+\mathrm{NO}$ & $\rightarrow \mathrm{O}+\mathrm{NO}$ & $k_{37}$ & $=1.5 \times 10^{-10}$ \\
\hline $\mathrm{O}\left({ }^{1} D\right)+\mathrm{O}$ & $\rightarrow \mathrm{O}+\mathrm{O}$ & $k_{38}$ & $=2.5 \times 10^{-11}$ \\
\hline $\mathrm{N}_{2}(A)+\mathrm{O}_{2}$ & $\rightarrow \mathrm{N}_{2}+\mathrm{O}_{2}$ & $k_{39}$ & $=4.0 \times 10^{-12}$ \\
\hline $\mathrm{N}_{2}(A)+\mathrm{NO}$ & $\rightarrow \mathrm{N}_{2}+\mathrm{NO}$ & $k_{40}$ & $=8.9 \times 10^{-11}$ \\
\hline $\mathrm{N}_{2}(A)+\mathrm{O}$ & $\begin{array}{l}\rightarrow \text { products } \\
\rightarrow \mathrm{N}_{2}+\mathrm{O}\left({ }^{1} S\right) \\
\rightarrow \mathrm{N}_{2}+\mathrm{O}\end{array}$ & $\begin{array}{l}k_{41} \\
k_{41 a} \\
k_{41 b}\end{array}$ & $\begin{array}{l}=2.8 \times 10^{-11} \\
=.36 \cdot k_{41} \\
=.64 \cdot k_{41}\end{array}$ \\
\hline
\end{tabular}


Table A.2. Recombination rates updated in the GLOW model. Adapted from Strickland et al. [1999] and updated with new rates that have become available.

\begin{tabular}{|c|c|c|c|c|}
\hline Reaction & & & Rate Coefficient $\left(\mathrm{cm}^{3} \mathrm{~s}^{-1}\right)$ & Reference \\
\hline $\mathrm{O}_{2}^{+}+e$ & $\begin{array}{l}\rightarrow \text { products } \\
\rightarrow \mathrm{O}\left({ }^{1} D\right)+\mathrm{O} \\
\rightarrow \mathrm{O}\left({ }^{1} D\right)+\mathrm{O}\left({ }^{1} D\right) \\
\rightarrow \mathrm{O}\left({ }^{1} S\right)+\mathrm{O}\left({ }^{1} D\right)\end{array}$ & $\begin{array}{l}\alpha_{1} \\
\alpha_{1 a} \\
\alpha_{1 b} \\
\alpha_{1 c}\end{array}$ & $\begin{array}{l}=1.95 \times 10^{-7} \tau_{e}^{-.7}, T_{e} \leq 1200^{\circ} \mathrm{K} \\
=1.93 \times 10^{-7} \tau_{e}^{-.61}, T_{e}>1200^{\circ} \mathrm{K} \\
=.609 \cdot \alpha_{1} \\
=.389 \cdot \alpha_{1} \\
=.002 \cdot \alpha_{1}\end{array}$ & {$[$ Pavlov, 2014] } \\
\hline $\mathrm{NO}^{+}+e$ & $\begin{array}{l}\rightarrow \text { products } \\
\rightarrow \mathrm{N}+\mathrm{O} \\
\rightarrow \mathrm{N}\left({ }^{2} D\right)+\mathrm{O}\end{array}$ & $\begin{array}{l}\alpha_{2 a} \\
\alpha_{2 b}\end{array}$ & $\begin{array}{l}=3.5 \times 10^{-7} \tau_{e}^{-.69}, T_{e} \leq 1200^{\circ} \mathrm{K} \\
=3.02 \times 10^{-7} \tau_{e}^{-.56}, T_{e}>1200^{\circ} \mathrm{K} \\
=.24 \cdot \alpha_{2} \\
=.76 \cdot \alpha_{2}\end{array}$ & {$[$ Pavlov, 2014] } \\
\hline $\mathrm{N}_{2}^{+}+e$ & $\begin{array}{l}\rightarrow \text { products } \\
\rightarrow \mathrm{N}\left({ }^{2} D\right)+\mathrm{N} \\
\rightarrow \mathrm{N}\left({ }^{2} D\right)+\mathrm{N}\left({ }^{2} D\right)\end{array}$ & $\begin{array}{l}\alpha_{3 a} \\
\alpha_{3 b}\end{array}$ & $\begin{array}{l}=2.2 \times 10^{-7} \tau_{e}^{-.39}, T_{e} \leq 1200^{\circ} \mathrm{K} \\
=1.95 \times 10^{-7} \tau_{e}^{-.57}, T_{e}>1200^{\circ} \mathrm{K} \\
=.88 \cdot \alpha_{3} \\
=.12 \cdot \alpha_{3}\end{array}$ & {$[$ Pavlov, 2014] } \\
\hline $\begin{array}{l}\mathrm{N}^{+}+e \\
\mathrm{O}^{+}+e\end{array}$ & $\begin{array}{l}\rightarrow \mathrm{N}+h v \\
\rightarrow \mathrm{O}+h v\end{array}$ & $\begin{array}{l}\alpha_{4} \\
\alpha_{5}\end{array}$ & $\begin{array}{l}=3.6 \times 10^{-12}\left(250 / T_{e}\right)^{{ }^{7}} \\
=3.7 \times 10^{-12}\left(250 / T_{e}\right)^{\cdot 7}\end{array}$ & $\begin{array}{l}\text { [Schunk and Nagy, 2009] } \\
\text { [Schunk and Nagy, 2009] }\end{array}$ \\
\hline
\end{tabular}

Table A.1: Continued

\begin{tabular}{llll}
\hline $\mathrm{N}_{2}(A)+\mathrm{N}$ & $\rightarrow$ products & $k_{42}=4.0 \times 10^{-11}$ \\
& $\rightarrow \mathrm{N}_{2}+\mathrm{N}\left({ }^{2} P\right)$ & $k_{42 a}=.9 \cdot k_{42}$ \\
$\left.\rightarrow \mathrm{N}_{2}+\mathrm{N}^{2} D\right)$ & $k_{42 b}=.1 \cdot k_{42}$ \\
$\mathrm{O}^{+}\left({ }^{2} D\right)+\mathrm{N}$ & $\rightarrow \mathrm{N}^{+}+\mathrm{O}$ & $k_{43}=7.5 \times 10^{-11}$ \\
$\mathrm{O}^{+}\left({ }^{2} P\right)+\mathrm{N}$ & $\rightarrow \mathrm{N}^{+}+\mathrm{O}$ & $k_{44}=1.0 \times 10^{-10}$ \\
$\mathrm{O}^{+}\left({ }^{2} P\right)+\mathrm{NO} \rightarrow \mathrm{NO}^{+}+\mathrm{O}$ & $k_{45}=2.9 \times 10^{-8}$ \\
$\mathrm{O}_{2}^{+}+\mathrm{N}_{2}$ & $\rightarrow \mathrm{NO}^{+}+\mathrm{NO}$ & $k_{46}=5.0 \times 10^{-16}$ \\
$\left.\mathrm{O}_{2}^{+}+\mathrm{N}^{2} D\right)$ & $\rightarrow \mathrm{N}^{+}+\mathrm{O}_{2}$ & $k_{47}=2.5 \times 10^{-10}$ \\
$\mathrm{O}+e$ & $\rightarrow \mathrm{O}^{-}+h v$ & $M_{1}=1.38 \times 10^{-15} e x p\left(-1.76 \times 10^{-4} T_{e}\right.$ \\
$\mathrm{O}^{+}+\mathrm{O}^{-}$ & $\rightarrow \mathrm{O}+\mathrm{O}^{*}$ & & $\left.+8.56 \times 10^{-8} T_{e}^{2}-1.43 \times 10^{-11} T_{e}^{3}\right)$ \\
$\mathrm{O}^{-}+\mathrm{O}$ & $\rightarrow \mathrm{O}_{2}+e$ & $M_{2}=1.0 \times 10^{-7}$
\end{tabular}

[1] Brekke [2013]; [2] Duff et al. [2003]; [3] Pandya and Joshipura [2014]; [4] Pavlov [2014]; [5] Rees and Lummerzheim [1989]; [6] Richards and Voglozin [2011]; [7] Sinnhuber et al. [2012]; [8] Strickland et al. [1999]; [9] Thirupathaiah and Singh [2014]; [10] Zettergren [2009] 
Table A.3. Electron quenching rates updated in the GLOW model. Adapted from Strickland et al. [1999] and updated with new rates that have become available.

\begin{tabular}{llcc}
\hline Reaction & & Rate Coefficient $\left(\mathrm{cm}^{3} \mathrm{~s}^{-1}\right)$ & Reference \\
\hline $\mathrm{O}^{+}\left({ }^{2} P\right)+e$ & $\rightarrow \mathrm{O}^{+}+e$ & $q_{1 a}=2.5 \times 10^{-8} \tau_{e}^{-.5}$ & [Pavlov, 2014] \\
& $\rightarrow \mathrm{O}^{+}\left({ }^{2} D\right)+e$ & $q_{1 b}=7.0 \times 10^{-8} \tau_{e}^{-.5}$ & \\
$\mathrm{O}^{+}\left({ }^{2} D\right)+e$ & $\rightarrow \mathrm{O}^{+}+e$ & $q_{2}=4.0 \times 10^{-8} \tau_{e}^{-.5}$ & [Pavlov, 2014] \\
$\mathrm{N}\left({ }^{2} P\right)+e$ & $\rightarrow \mathrm{N}+e$ & $q_{3 a}=1.6 \times 10^{-12} T_{e}^{.85}$ & [Strickland et al., 1999] \\
& $\rightarrow \mathrm{N}\left({ }^{2} D\right)+e$ & $q_{3 b}=9.5 \times 10^{-9}$ & \\
$\mathrm{~N}\left({ }^{2} D\right)+e$ & $\rightarrow \mathrm{N}+e$ & $q_{4}=3.8 \times 10^{-12} T_{e}^{.81}$ & [Pandya and Joshipura, 2014] \\
$\mathrm{O}\left({ }^{1} S\right)+e$ & $\rightarrow \mathrm{O}+e$ & $q_{5 a}=1.56 \times 10^{-9} \tau_{e}^{.94}$ & [Bhardwaj and Raghuram, 2012] \\
& $\rightarrow \mathrm{O}\left({ }^{1} D\right)+e$ & $q_{5 b}=8.56 \times 10^{-9}$ & \\
$\mathrm{O}\left({ }^{1} D\right)+e$ & $\rightarrow \mathrm{O}+e$ & $q_{6}=8.1 \times 10^{-10} \tau_{e}^{.5}$ & [Bhardwaj and Raghuram, 2012] \\
\hline
\end{tabular}

Table A.4. Radiative decay rates updated in the GLOW model. Adapted from Strickland et al. [1999] and updated with new rates that have become available.

\begin{tabular}{lllc}
\hline Reaction & & $A$ Coefficient $\left(\mathrm{s}^{-1}\right)$ & Reference \\
\hline $\mathrm{O}^{+}\left({ }^{2} P\right)$ & $\rightarrow \mathrm{O}^{+}\left({ }^{4} S^{0}\right)+h v(2470 \AA)$ & $A_{2470}=4.70 \times 10^{-2}$ & [Zettergren, 2009] \\
& $\rightarrow \mathrm{O}^{+}\left({ }^{2} D\right)+h v(7320 \AA)$ & $A_{7320}=9.91 \times 10^{-2}$ & [Zettergren, 2009] \\
& $\rightarrow \mathrm{O}^{+}\left({ }^{2} D\right)+h v(7330 \AA)$ & $A_{7330}=7.49 \times 10^{-2}$ & [Zettergren, 2009] \\
$\mathrm{O}^{+}\left({ }^{2} D\right)$ & $\rightarrow \mathrm{O}^{+}\left({ }^{4} S^{0}\right)+h v(3727 \AA)$ & $A_{3727}=8.89 \times 10^{-5}$ & {$[$ [Strickland et al., 1999] } \\
$\mathrm{N}^{+}\left({ }^{2} P\right)$ & $\rightarrow \mathrm{N}^{+}\left({ }^{4} S^{0}\right)+h v(3466 \AA)$ & $A_{3466}=6.50 \times 10^{-3}$ & {$[$ Pandya and Joshipura, 2014] } \\
& $\rightarrow \mathrm{N}^{+}\left({ }^{2} D\right)+h v(10400 \AA)$ & $A_{10400}=3.45 \times 10^{-3}$ & [Pandya and Joshipura, 2014] \\
$\mathrm{N}^{+}\left({ }^{2} D\right)$ & $\rightarrow \mathrm{N}^{+}\left({ }^{4} S^{0}\right)+h v(5200 \AA)$ & $A_{5200}=6.60 \times 10^{-6}$ & [Pandya and Joshipura, 2014] \\
$\left.\mathrm{O}^{1} S\right)$ & $\rightarrow \mathrm{O}^{+}\left({ }^{3} P\right)+h v(2972 \AA)$ & $A_{2972}=.075$ & [Pandya and Joshipura, 2014] \\
& $\rightarrow \mathrm{O}^{+}\left({ }^{1} D\right)+h v(5577 \AA)$ & $A_{5577}=1.26$ & [Pandya and Joshipura, 2014] \\
$\mathrm{O}\left({ }^{1} D\right)$ & $\rightarrow \mathrm{O}^{+}\left({ }^{3} P\right)+h v(6300 \AA)$ & $A_{6300}=6.44 \times 10^{-3}$ & [Bhardwaj and Raghuram, 2012] \\
& $\rightarrow \mathrm{O}^{+}\left({ }^{3} P\right)+h v(6364 \AA)$ & $A_{6364}=2.15 \times 10^{-3}$ & [Bhardwaj and Raghuram, 2012] \\
$\mathrm{N}_{2}(A)$ & $\rightarrow \mathrm{N}_{2}(X)+h v(\mathrm{VK})$ & $A_{V K}=.352$ & [Strickland et al., 1999] \\
\hline
\end{tabular}




\section{Acknowledgments}

The imagers used in this work were funded through a National Science Foundation Major Research Instrumentation grant (ATM-0923412) to Southwest Research Institute (PI: M. Samara) from 2009 to 2012. Guy Grubbs II was supported by NASA grant NNX12AE76G and Robert Michell was supported by NASA grant NNX15AG06G. APES was designed, fabricated, and calibrated at Southwest Research Institute (SwRI) prior to flight. We thank Stan Solomon and Michael Hirsch, National Center for Atmospheric Research, for the development of the GLOW code in Fotran (http://download.hao.ucar.edu/pub/stans/glow/code/glowv0.98/) and Python (https://github.com/scienceopen/glowaurora). The National Center for Atmospheric Research is funded by the National Science Foundation. We thank NASA/GSFC's OMNIWeb service and Dieter Bilitza for the IRI Fortran source code and atmospheric data (http://irimodel.org/IRI-2016/). We thank Matthew Zettergren for helpful suggestions and comments on the presentation of this work. The MOOSE and APES data shown are available upon request from the authors.

\section{References}

Anderson, D. N., J. M. Forbes, and M. Codrescu (1989), A fully analytic, low- and middle-latitude ionospheric model, Journal of Geophysical Research: Space Physics, 94(A2), 1520-1524, doi:10.1029/JA094iA02p01520.

Bhardwaj, A., and S. Raghuram (2012), A coupled chemistry-emission model for atomic oxygen green and red-doublet emissions in the Comet C/1996 B2 Hyakutake, The Astrophysical Journal, 748(13), 1-18.

Bilitza, D., D. Altadill, Y. Zhang, C. Mertens, V. Truhlik, P. Richards, L.-A. McKinnell, and B. Reinisch (2014), The international reference ionosphere 2012 - a model of international collaboration, J. Space Weather Space Clim., 4, A07, doi: $10.1051 / \mathrm{swsc} / 2014004$.

Birn, J., A. Artemyev, D. Baker, M. Echim, M. Hoshino, and L. Zelenyi (2012), Particle acceleration in the magnetotail and aurora, Space Science Reviews, 173(1-4), 49-102, doi:10.1007/s11214-012-9874-4.

Brekke, A. (2013), The aurora, in Physics of the Upper Polar Atmosphere, pp. 317-369, Springer.

Duff, J., H. Dothe, and R. Sharma (2003), On the rate coefficient of the n (2d)+ o2-> no+ o reaction in the terrestrial thermosphere, Geophysical research letters, 30(5).

Fang, X., C. E. Randall, D. Lummerzheim, S. C. Solomon, M. J. Mills, D. R. Marsh, C. H. Jackman, W. Wang, and G. Lu (2008), Electron impact ionization: A new parameterization for $100 \mathrm{ev}$ to $1 \mathrm{mev}$ electrons, Journal of Geophysical Research: Space Physics, 113(A9).

Grubbs, G., R. Michell, M. Samara, D. Hampton, and J.-M. Jahn (2016), A synthesis of star calibration techniques for ground-based narrowband electron-multiplying chargecoupled device imagers used in auroral photometry, Journal of Geophysical Research: Space Physics, 121(6), 5991-6002.

Grubbs II, G., R. Michell, M. Samara, D. Hampton, and J.-M. Jahn (2017), Predicting electron population characteristics in 2-d using multi-spectral ground-based imaging, Geophysical Research Letters, 44, doi:10.1002/2017GL075873, 2017 GL075873.

Gustafsson, G., N. Papitashvili, and V. Papitashvili (1992), A revised corrected geomagnetic coordinate system for epochs 1985 and 1990, Journal of Atmospheric and Terrestrial Physics, 54(11), 1609 - 1631, doi:http://dx.doi.org/10.1016/0021-9169(92)90167-J.

Hecht, J., D. Strickland, and M. Conde (2006), The application of ground-based optical techniques for inferring electron energy deposition and composition change during auroral precipitation events, Journal of Atmospheric and Solar-Terrestrial Physics, 68(13), $1502-1519$.

Hecht, J., T. Mulligan, D. Strickland, A. Kochenash, Y. Murayama, Y.-M. Tanaka, D. Evans, M. Conde, E. Donovan, F. Rich, et al. (2008), Satellite and ground-based 
observations of auroral energy deposition and the effects on thermospheric composition during large geomagnetic storms: 1. great geomagnetic storm of 20 november 2003, Journal of Geophysical Research: Space Physics, 113(A1).

Jones, R., and M. Rees (1973), Time dependent studies of the aurora-i. ion density and composition, Planetary and Space Science, 21(4), 537-557.

Kaeppler, S., D. Hampton, M. Nicolls, A. Strømme, S. Solomon, J. Hecht, and M. Conde (2015), An investigation comparing ground-based techniques that quantify auroral electron flux and conductance, Journal of Geophysical Research: Space Physics, 120(10), 9038-9056.

Kelley, M. C. (2009), The Earth's Ionosphere: Plasma Physics $\mathcal{F}$ Electrodynamics, vol. 96, Academic Press.

Liang, J., E. Donovan, B. Jackel, E. Spanswick, and M. Gillies (2016), On the 630âĂL'nm red-line pulsating aurora: Red-line emission geospace observatory observations and model simulations, Journal of Geophysical Research: Space Physics, 121(8), 7988-8012, doi:10.1002/2016JA022901, 2016JA022901.

Lummerzheim, D. (1987), Electron transport and optical emissions in the aurora, Ph.D. thesis, Alaska Univ., Fairbanks (USA).

Lummerzheim, D., and J. Lilensten (1994), Electron transport and energy degradation in the ionosphere: evaluation of the numerical solution, comparison with laboratory experiments and auroral observations, Annales Geophysicae, 12(10/11), 1039-1051, doi: 10.1007/s00585-994-1039-7.

Lummerzheim, D., M. Rees, and H. Anderson (1989), Angular dependent transport of auroral electrons in the upper atmosphere, Planetary and Space Science, 37(1), 109-129.

Marsh, D. R., S. C. Solomon, and A. E. Reynolds (2004), Empirical model of nitric oxide in the lower thermosphere, Journal of Geophysical Research: Space Physics, 109(A7), doi:10.1029/2003JA010199.

Meier, R. R., D. J. Strickland, J. H. Hecht, and A. B. Christensen (1989), Deducing composition and incident electron spectra from ground-based auroral optical measurements: A study of auroral red line processes, Journal of Geophysical Research: Space Physics, 94(A10), 13,541-13,552, doi:10.1029/JA094iA10p13541.

Michell, R. G., M. Samara, G. Grubbs, K. Ogasawara, G. Miller, J. A. Trevino, J. Webster, and J. Stange (2016), Apes: Acute precipitating electron spectrometer: A high time-resolution mono-directional magnetic deflection electron spectrometer, Journal of Geophysical Research: Space Physics, pp. n/a-n/a, doi:10.1002/2016JA022637, 2016 JA022637.

Ni, B., J. Liang, R. M. Thorne, V. Angelopoulos, R. B. Horne, M. Kubyshkina, E. Spanswick, E. F. Donovan, and D. Lummerzheim (2012), Efficient diffuse auroral electron scattering by electrostatic electron cyclotron harmonic waves in the outer magnetosphere: A detailed case study, Journal of Geophysical Research: Space Physics, 117(A1), n/a-n/a, doi:10.1029/2011JA017095, a01218.

Pandya, S. H., and K. N. Joshipura (2014), Ionization of metastable nitrogen and oxygen atoms by electron impact: Relevance to auroral emissions, Journal of Geophysical Research: Space Physics, 119(3), 2263-2268, doi:10.1002/2013JA019208, 2013JA019208.

Paschmann, G., S. Haaland, and R. A. Treumann (2003), Auroral Plasma Physics, Springer.

Pavlov, A. (2014), Photochemistry of ions at d-region altitudes of the ionosphere: A review, Surveys in Geophysics, 35(2), 259-334.

Picone, J. M., A. E. Hedin, D. P. Drob, and A. C. Aikin (2002), NRLMSISE-00 empirical model of the atmosphere: Statistical comparisons and scientific issues, Journal of Geophysical Research: Space Physics, 107(A12), SIA 15-1-SIA 15-16, doi: 10.1029/2002JA009430.

Qian, L., A. G. Burns, B. A. Emery, B. Foster, G. Lu, A. Maute, A. D. Richmond, R. G. Roble, S. C. Solomon, and W. Wang (2014), The NCAR TIE-GCM: A community model of the coupled thermosphere/ionosphere system, Modeling the Ionosphere- 
Thermosphere System, 201, 73-83.

Rees, M., and R. Jones (1973), Time dependent studies of the aurora-ii. spectroscopic morphology, Planetary and Space Science, 21(7), 1213-1235.

Rees, M., and D. Lummerzheim (1989), Characteristics of auroral electron precipitation derived from optical spectroscopy, Journal of Geophysical Research: Space Physics (1978-2012), 94(A6), 6799-6815.

Richards, P., and D. Voglozin (2011), Reexamination of ionospheric photochemistry, Journal of Geophysical Research: Space Physics, 116(A8).

Schunk, R., and A. Nagy (2009), Ionospheres: Physics, Plasma Physics, and Chemistry, Cambridge University Press.

Shroll, R. M., S. Adler-Golden, J. W. Duff, and J. H. Brown (2003), User's manual for SAG-2 SHARC/SAMM atmosphere generator, Tech. rep., DTIC Document.

Sinnhuber, M., H. Nieder, and N. Wieters (2012), Energetic particle precipitation and the chemistry of the mesosphere/lower thermosphere, Surveys in Geophysics, 33(6), 12811334.

Solomon, S. C. (1989), Auroral excitation of the $n_{2} 2 \mathrm{p}(0,0)$ and $\mathrm{vk}(0,9)$ bands, Journal of Geophysical Research, 94, 17,215-17,222.

Solomon, S. C. (2001), Auroral particle transport using monte carlo and hybrid methods, Journal of Geophysical Research, 106, 107-116.

Solomon, S. C. (2017), Global modeling of thermospheric airglow in the far ultraviolet, Journal of Geophysical Research: Space Physics, 122(7), 7834-7848, doi: 10.1002/2017JA024314, 2017JA024314.

Solomon, S. C., P. B. Hays, and V. J. Abreu (1988), The auroral 6300 å emission: Observations and modeling, Journal of Geophysical Research: Space Physics, 93(A9), 98679882.

Steele, D. P., and D. J. McEwen (1990), Electron auroral excitation efficiencies and intensity ratios, Journal of Geophysical Research: Space Physics, 95(A7), 10,321-10,336, doi:10.1029/JA095iA07p10321.

Strickland, D., R. Meier, J. Hecht, and A. Christensen (1989), Deducing composition and incident electron spectra from ground-based auroral optical measurements: Theory and model results, Journal of Geophysical Research: Space Physics (1978-2012), 94(A10), $13,527-13,539$.

Strickland, D., B. Basu, J. Jasperse, and R. Daniell (1992), A linear transport theory for the electron-proton-hydrogen atom aurora, in J. Geophys. Res.

Strickland, D., J. Bishop, J. Evans, T. Majeed, P. Shen, R. Cox, R. Link, and R. Huffman (1999), Atmospheric ultraviolet radiance integrated code (auric): theory, software architecture, inputs, and selected results, Journal of Quantitative Spectroscopy and Radiative Transfer, 62(6), 689-742, doi:http://dx.doi.org/10.1016/S0022-4073(98)00098-3.

Thébault, E., C. C. Finlay, C. D. Beggan, P. Alken, J. Aubert, O. Barrois, F. Bertrand, T. Bondar, A. Boness, L. Brocco, E. Canet, A. Chambodut, A. Chulliat, P. Coïsson, F. Civet, A. Du, A. Fournier, I. Fratter, N. Gillet, B. Hamilton, M. Hamoudi, G. Hulot, T. Jager, M. Korte, W. Kuang, X. Lalanne, B. Langlais, J.-M. Léger, V. Lesur, F. J. Lowes, S. Macmillan, M. Mandea, C. Manoj, S. Maus, N. Olsen, V. Petrov, V. Ridley, M. Rother, T. J. Sabaka, D. Saturnino, R. Schachtschneider, O. Sirol, A. Tangborn, A. Thomson, L. Tøffner-Clausen, P. Vigneron, I. Wardinski, and T. Zvereva (2015), International geomagnetic reference field: the 12th generation, Earth, Planets and Space, 67(1), 1-19, doi:10.1186/s40623-015-0228-9.

Thirupathaiah, P., and V. Singh (2014), An updated model of atomic oxygen redline dayglow emission, Advances in Space Research, 54(6), 939 - 945, doi: http://dx.doi.org/10.1016/j.asr.2014.05.022.

Zettergren, M., K. Lynch, D. Hampton, M. Nicolls, B. Wright, M. Conde, J. Moen, M. Lessard, R. Miceli, and S. Powell (2014), Auroral ionospheric f region density cavity formation and evolution: Mica campaign results, Journal of Geophysical Research: Space Physics, 119(4), 3162-3178, doi:10.1002/2013JA019583. 
Zettergren, M. D. (2009), Model-based optical and radar remote sensing of transport and composition in the auroral ionosphere, Ph.D. thesis, Boston University. 